\title{
Triatoma williami in intradomiciliary environments of urban areas in Mato Grosso State, Brazil: domiciliation process of a wild species?
}

Mirian Francisca Martins ${ }^{1 *} \mathbb{D}$, Sinara Cristina de Moraes ${ }^{1}$, Jader Oliveira², Janaina Cipriana dos Santos ${ }^{3}$, Ludier Kesser Santos-Silva ${ }^{3}$ and Cleber Galvão ${ }^{4}$

\begin{abstract}
Background: Triatomines in Latin America are natural Chagas disease (ChD) vectors. Triatomine domiciliation is one of the main factors increasing the occurrence risk of this disease in humans. There are 66 triatomine species in Brazil, with three genera of significant epidemiological importance-Panstrongylus, Rhodnius, and Triatoma. Among the Triatoma species, Triatoma williami, a wild species, has been reported in Goiás, Mato Grosso, and Mato Grosso do Sul. In the Barra do Garças, Mato Grosso, the invasion by triatomines has been reported, with T. williami being the most common species. This study aimed to survey triatomine fauna and determine the Trypanosoma cruzi natural infection rates in triatomines in the urban area of Barra do Garças, Mato Grosso, Brazil.
\end{abstract}

Methods: Triatomine specimens were sampled by passive surveillance or active search by agents combating endemic diseases from 2019 to 2020. A parasitological feces diagnosis was performed to detect the presence of $T$. cruzi after the specimens were identified. Concerning T. cruzi identification, molecular diagnosis and genetic sequencing were performed to determine the strain, also called discrete typing units (DTUs).

Results: The 211 triatomines were collected, distributed in specimens of T. williami (84.4\%), P. geniculatus (3.3\%), P. diasi (1.4\%), and $R$. neglectus (10.9\%). Two colonies of T. williami were found through morphological analyses. These insects were sampled inside domiciles in an urban area neighboring Jardim Pitaluga ( $15^{\circ} 51^{\prime} 57.7^{\prime \prime} \mathrm{N}, 052^{\circ} 16^{\prime} 04.5 \mathrm{E}$ ). The records were sampled in September 2019 and January 2021. The rate of natural infection by T. cruzi was 39.4\%. Two T. williami specimens from the sampled colonies were positive for the T. cruzi strain DTU IV.

Conclusions: This is the first time that T. williami has been confirmed in an urban area of Barra do Garças, Mato Grosso, Brazil. Further studies are needed for a clearer understanding of the ecology of this species for prevention and control mechanisms since its sampled specimens had a high rate of natural infection by T. cruzi.

Keywords: Triatominae, Triatoma williami, Colonization, Trypanosoma cruzi, Chagas disease, Surveillance program

\footnotetext{
${ }^{*}$ Correspondence: mirianfranmartins@gmail.com

1 Department of Environmental Health Surveillance, State Health

Secretary of Mato Grosso-SESMT, Amaro Leite 474, Barra do Garças, MT 78600-027, Brazil

Full list of author information is available at the end of the article
} permits use, sharing, adaptation, distribution and reproduction in any medium or format, as long as you give appropriate credit to the original author(s) and the source, provide a link to the Creative Commons licence, and indicate if changes were made. The images or other third party material in this article are included in the article's Creative Commons licence, unless indicated otherwise in a credit line to the material. If material is not included in the article's Creative Commons licence and your intended use is not permitted by statutory regulation or exceeds the permitted use, you will need to obtain permission directly from the copyright holder. To view a copy of this licence, visit http://creativecommons.org/licenses/by/4.0/. The Creative Commons Public Domain Dedication waiver (http://creativeco mmons.org/publicdomain/zero/1.0/) applies to the data made available in this article, unless otherwise stated in a credit line to the data. 


\section{Graphical Abstract}

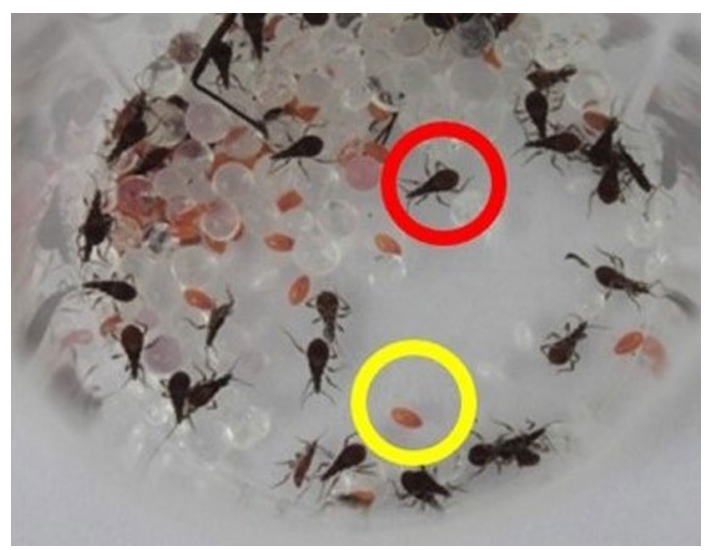

\section{Background}

The blood-sucking Triatominae subfamily (Hemiptera, Reduviidae) are vectors of Trypanosoma cruzi (Chagas, 1909) (Kinetoplastida, Trypanosomatidae), which causes Chagas disease (ChD). A total of 154 extant and three fossil species are comprised within five tribes and 18 genera of this subfamily [1]. In Brazil, 66 triatomine species have been previously recorded [2-6]. Three genera have particularly significant sanitary importance and are related to the transmission of $T$. cruzi to humans: Panstrongylus, Rhodnius, and Triatoma [2, 7-10].

Vectorial transmission by Triatoma infestans was officially eliminated from Brazil in 2006, and efforts were made to halt the transmission of $\mathrm{ChD}$ by non-native vectors [11]. Despite this significant achievement, with such a "ChD vector elimination certification", a false idea may be given that disease transmission does not exist [12]. Native triatomine species are potential vectors of T. cruzi and can invade and colonize artificially in domestic and peridomestic environments [13].

Triatominae domestication may be envisaged as an extension of the evolutionary route from predator to nest-dwelling bloodsucker, where the domestic habitat represents a particular type of vertebrate 'nest' [14]. The infestation and density index have often been considered indicators of the level of intrusion of a species into the domestic habitat, while the colonization index can be viewed as a measure of its domiciliation or domestication [15]. Domiciliary species are characterized by developing their life cycle inside domiciles or peridomicile structures. This assumption will be confirmed if adults, nymphs, eggs, and exuviae are caught [15].

Triatominae domiciliation is one of the main factors in the increasing transmission risk of $T$. cruzi to humans [16]. Anthropogenic morphoclimatic alterations propel the domiciliation process and dispersal of triatomines and can be interpreted as a survival strategy for the species [17]. Silveira et al. [18] reported that the domiciliation process results from factors that may promote the invasion and progressive adaptation of triatomines to the human domicile and may be related to the environment and the inherent characteristics of the vector. The domiciliation could be accelerated by the opportunism of wild triatomine species in the scenario of natural food source scarcity. The human demographic shift is partially responsible for the changes in vectorial transmission. With such a shift promoting unfavorable environmental changes and subsequent rarefaction in wild fauna, triatomines are led to move to highly artificial habitats where various hiding places, stability, and abundance of food throughout the year exist [19].

The trends toward domesticity seem to be associated with behavioral plasticity, reducing the genetic repertoire of specimens, and increasing developmental instability. These conditions make triatomine species and populations more efficient vectors $[19,20]$.

For a long time, triatomine species have been classified according to their adaptation to human domiciles. This classification usually occurs in three groups, with triatomine species classified as domiciliary, peridomiciliary, and wild. Noireau et al. [21] proposed four categories of adaptation of triatomine species to human domiciles: sylvatic, intrusive, domiciliary, and domestic species. Such definitions have been the most widely accepted and are used in the literature to classify many triatomine species [15].

From the vector control perspective, it is of significant importance to determine precisely three aspects of the relationship between triatomines and 
humans: (i) the prevalence of sylvatic populations of triatomines, (ii) the level of intrusion of these sylvatic populations in peridomicile and inside domicile, and (iii) the domiciliation or domestication levels in peridomicile and domicile [15]. Nowadays, attention has been focused on the domiciliation of species, considered sylvatic because of increasing reports of wild species invading the domicile and peridomicile in South American countries [22-24]. Invasions by at least 10 species have been reported in the literature in the last few decades, increasing the risk of intradomiciliary colonies in South American countries, such as Brazil, Bolivia, Colombia, and Venezuela (Additional file 1: Table S1).

Triatoma williami Galvão, Souza e Lima, 1965 is a wild species reported in the Brazilian states of Goiás, Mato Grosso, and Mato Grosso do Sul [2, 25, 26]. The risk of domiciliation of this species was previously hypothesized by Andrade-Neto et al. [27] through interviews with residents. Here, the domiciliation of this species was demonstrated by observing all of its life stages, including eggs, within the domiciles.

This study aimed to survey triatomine fauna and determine the natural infection rates in Barra do Garças municipality, Mato Grosso State in Brazil. This study would provide relevant information for improving the $\mathrm{ChD}$ monitoring activities of sanitary authorities.

\section{Methods}

\section{Study area}

This study was conducted in an urban area of Barra do Garças, Mato Grosso, Brazil. This municipality $\left(15^{\circ}\right.$ $51.98^{\prime} \mathrm{S}, 052^{\circ} 16.29^{\prime} \mathrm{W}, 395 \mathrm{~m}$ altitude) is located in the eastern Mato Grosso region bordering the state of Goiás, also known as Vale do Araguaia. The municipality has a population of 56,423 inhabitants and a territorial area of $9079 \mathrm{~km}^{2}$ [28] (Fig. 1).

Barra do Garças has a different ecological context, given its proximity to the Parque Estadual da Serra Azul conservation unit facility (PESA abbreviation in Portuguese) [29]. PESA ( $\left.15^{\circ} 49^{\prime} 15^{\prime \prime} \mathrm{S} 52^{\circ} 12^{\prime} 57^{\prime \prime} \mathrm{W}\right)$ has 11.002 ha, with several Brazilian Cerrado phytophysiognomies (e.g., gallery forests, semi-deciduous forests, typical cerrado, and predominantly rupestrian Cerrado) [30] (Additional file 2: Fig. S1).

The Brazilian Cerrado biome is characterized by spatial heterogeneity and high plant and insect endemism $[31,32]$. This biome is considered a world biodiversity hotspot. The climate is characterized by two seasons, dry winters and rainy summers, corresponding to the Aw climatic type, according to the Köppen classification [33]. Annually, the climate in this region has a $60 \%$ annual average humidity and an annual average temperature of $20-27^{\circ} \mathrm{C}$.

\section{The health organization}

The headquarters of the municipality are organized in 53 neighborhoods. The city health secretary has 45 endemic

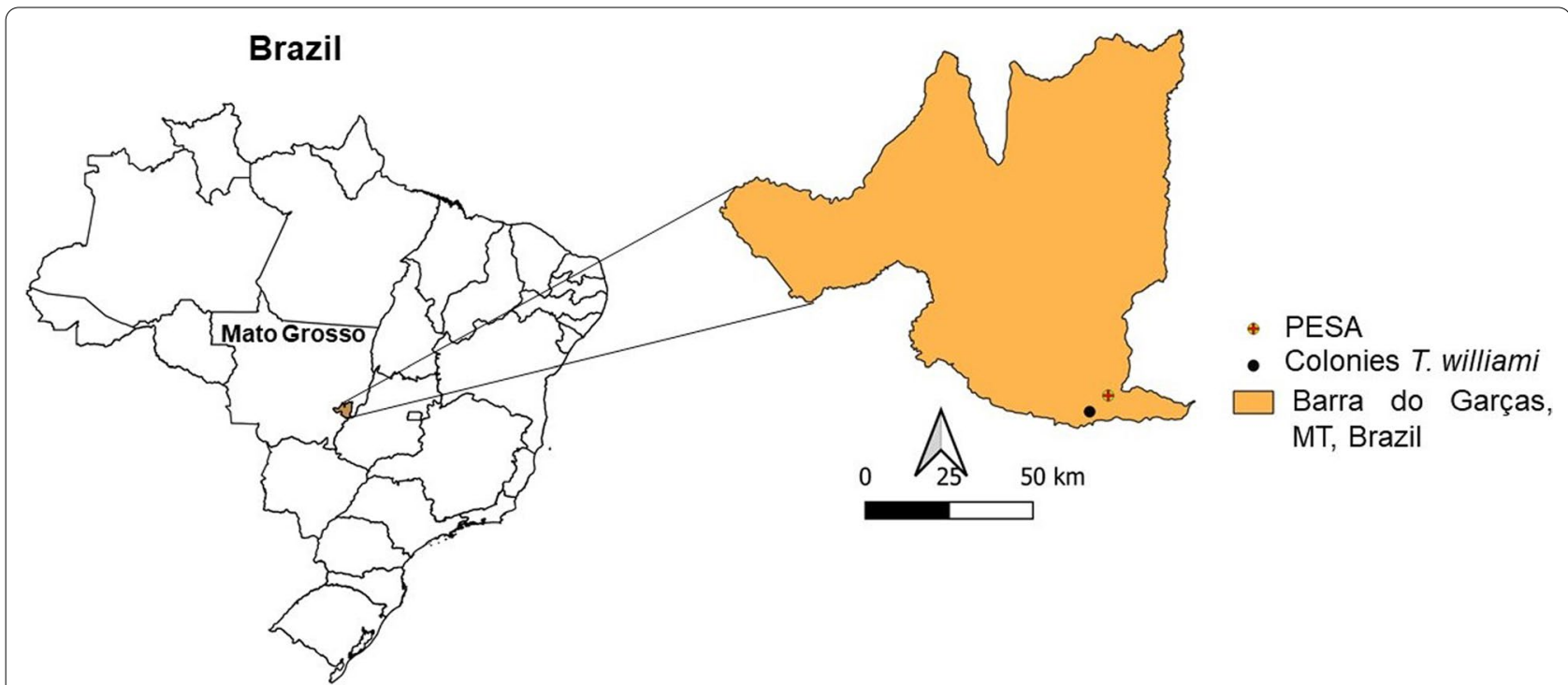

Fig. 1 Municipality of Barra do Garças, Mato Grosso, Brazil. Adapted from the Brazilian Institute of Geography and Statistics (Instituto Brasileiro de

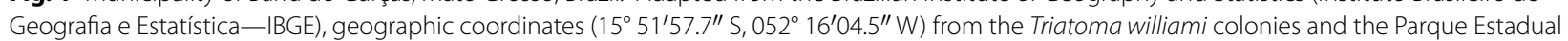

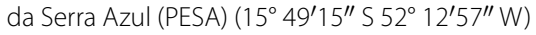


control field agents to perform health surveillance and vector control activities. Three of these agents work in the surveillance and control of $\mathrm{ChD}$ vectors. The action of these agents consists of performing health education for $\mathrm{ChD}$ prevention and domicile inspections, both in the inner and the peridomicile. If triatomine specimens are found, chemical control is performed using residual action insecticides made available by the Brazilian Ministry of Health.

Barra do Garças is comprised in the health region Garças Araguaia. This city is the location of the regional health office of Barra do Garças and the Entomology Laboratory at the Regional Health Office (ERSBG abbreviation in Portuguese) from the state health secretary of Mato Grosso (SESMT abbreviation in Portuguese). Monthly spreadsheets from the ChD control program (PCDCh abbreviation in Portuguese) containing data on the activities were sent to ERSBG by SESMT. With this information, PCDCh was monitored by SESMT. The most frequent specimens, vectorial density, and natural rate of infection were analyzed in ERSBG. Investigations of whether there were seasonal patterns for species and the construction of historical series, among other activities, were also conducted by ERSBG.

\section{Taxonomic identification of insects}

The analyzed insects were collected via passive surveillance by residents or active search by agents combating endemic diseases on scheduled domicile visits from 2019 to 2020. The second colony was found in January 2021 and entered in this analysis without waiting for the ERSBG database to close at the end of each year.

The inhabitants usually collected triatomine specimens found in their domiciles. These people informed the health workers or delivered the specimens directly to the ERSBG. All the sampled material was analyzed in this facility. Specimen identification was made using dichotomous keys $[2,16]$. The identification of these insects as $T$. williami was conducted based on the external morphological characteristics of the head, wing, abdomen, and external female genitalia (Additional file 3: Fig. S2A-E).

\section{Natural infection by T. cruzi Parasitological diagnosis}

A parasitological examination of fresh feces from livesampled specimens with intestinal contents was performed. For this purpose, $5 \mu \mathrm{l}$ of intestinal content plus two drops of phosphate-buffered saline ( $\mathrm{pH}$ 7.2) between slides and coverslips were observed under a microscope optical at $400 \times$. This procedure is the conventional diagnosis recommended by the Ministry of Health in Brazil.

\section{Molecular diagnosis}

For the analysis of natural infection by T. cruzi, conventional polymerase chain reactions (PCR) were performed, as previously described by Brígido et al. [34] using oligonucleotides P21 fw (5'-AACGCACCA TCAATCTTTTG-3') and P21 rv (5'-CGTCGCATT CCTCATTTCTTC-3') that amplify a 65 bp fragment from the genomic region of the parasite. For the discrete type of unit (DTU) identification of T. cruzi, PCR was performed according to Consetino et al. [35]. For this analysis, oligonucleotides TcSC5D-forward 5'-GGACGTGGCGTTTGATTTAT- $3^{\prime}$ and TcSC5Dreverse $5^{\prime}$-TCCCATCTTCTTCGTTGACT-3' were used. An amplicon of 832 bp from the TcSC5D gene was produced with these oligonucleotides. The amplicons were sequenced using an ABI3730xl Genetic Analyzer (Applied Biosystems: Life Technologies Corporation, 5791 Van Allen Way, Carlsbad, California 92008). The T. cruzi TcSC5D gene sequences were analyzed using the Clustal Omega tool [36] to discriminate the DTUs TcI from TcVI using the polymorphic sites described by Consentino et al. [35].

\section{T. williami domiciliary colonization}

In September 2019, a request from a resident was attended by the $\mathrm{ChD}$ surveillance team, where a triatomine entomological survey was conducted. In one bed within this domicile, the field agents found the first T. williami colony containing adults, first instar nymphs, and eggs.

In January 2021, the agents performed another entomological research in that domicile. This time, the agents found adults, nymphs of different stadium, and eggs. As recommended, the agents carried out residual chemical control in this domicile, and subsequent more T. williami specimens from different stages of development were found.

\section{Data analysis}

The data were tabulated and analyzed using Excel 2016 for Windows ${ }^{\circledR}$ (Microsoft, Redmond, USA). The following entomological indicators were considered in the analysis: number of triatomines captured (males, females, and nymphs), number of triatomines found inside and outside of the domiciles, and number of infected triatomines.

Descriptive statistics were used to obtain the absolute and relative frequencies. The absolute frequency was estimated as the number of triatomine collected by specie and to calculate the relative frequencies used the absolute frequencies by the total number of triatomines. 
Only entomologic indices are considered risk factors associated with T. cruzi transmission. The results are presented in percentages and indices.

The triatomine prevalence was estimated as the number of triatomine specimens by the total number of triatomines collected. The natural infection rate was calculated from the number of infected triatomines/number of triatomines examined $\times 100$.

\section{Results}

Triatomine species invading dwellings in the urban area of Barra do Garças

A total of 211 triatomines were collected during this study, 155 in 2019 and 56 in 2020. Specimens of T. williami (84.4\%), P. geniculatus (3.3\%), P. diasi (1.4\%), and $R$. neglectus $(10.9 \%)$ were found during the surveys. Since 2013, there have been records of triatomines invading domiciles in urban areas in Barra do Garças, Mato Grosso, Brazil (Additional file 4: Fig. S3).

T. williami has been registered in eight neighborhoods in the urban area of Barra do Garças, Mato Grosso, Brazil. In 2019 and 2020 (Table 1), the highest infestations recorded were found in boundaries neighborhoods of the PESA in descending order: Jd. Amazônia I-BNH, Jd. Pitaluga, Jd. Araguaia and Santo Antônio.

\section{Population structure and environments occupied by Triatoma williami}

The adult T. williami population was 75 females and 19 males in 2019 and 30 females and 10 males in 2020. The female-to-male ratio was not within the expected 1:1 pattern: $3.9(75 / 19)$ and $3(30 / 10)$ times more females than males. For immatures, we had 41 first-stage nymphs, one second-stage nymph, and one-fifth-stage

Table 1 Distribution of the collected Triatoma williami specimens by neighborhood in Barra do Garças, Mato Grosso, Brazil, in 2019 and 2020

\begin{tabular}{|c|c|c|c|c|}
\hline \multirow{2}{*}{$\begin{array}{l}\text { T. williami abundance by } \\
\text { neighborhood }\end{array}$} & \multicolumn{2}{|c|}{2019} & \multicolumn{2}{|c|}{2020} \\
\hline & AF & RF (\%) & AF & RF (\%) \\
\hline Jd. Amazônia I-BNH & 57 & 41.6 & 32 & 78.0 \\
\hline Jd. Pitaluga & 72 & 52.6 & 9 & 22.0 \\
\hline Jd. Araguaia & 2 & 1.5 & 0 & 0.0 \\
\hline Santo Antônio & 2 & 1.5 & 0 & 0.0 \\
\hline Monte Sinai & 1 & 0.7 & 0 & 0.0 \\
\hline Jd. Amazônia II & 1 & 0.7 & 0 & 0.0 \\
\hline Jd. Piracema & 1 & 0.7 & 0 & 0.0 \\
\hline São Sebastião & 1 & 0.7 & 0 & 0.0 \\
\hline Total & 137 & 100.0 & 41 & 100.0 \\
\hline
\end{tabular}

Places in bold: boundary neighborhoods of the PESA

$A F$ absolute frequency, $R F$ relative frequency
Table 2 The percentage of Triatoma williami collected from 2019 to 2020 in Barra do Garças, Mato Grosso, Brazil, from 2019 to 2020 in each environment

\begin{tabular}{lcccc}
\hline & \multicolumn{3}{l}{ Number of Triatoma williami } & \\
\cline { 2 - 4 } Environment & $\mathbf{2 0 1 9}$ & $\mathbf{2 0 2 0}$ & Total & $\%$ \\
\hline Indoor & & & & \\
Bedroom & 60 & 6 & 66 & 37.1 \\
Living room & 15 & 8 & 23 & 12.9 \\
Kitchen & 11 & 3 & 14 & 7.9 \\
Bathroom & 2 & 0 & 2 & 1.1 \\
& 88 & 17 & 105 & 59 \\
Peridomicile & & & & \\
Balcony & 29 & 6 & 35 & 19.7 \\
Garage & 1 & 0 & 1 & 0.6 \\
Barbecue grill & 1 & 0 & 1 & 0.6 \\
Upper balcony & 0 & 3 & 3 & 1.7 \\
Subtotal & 31 & 9 & 40 & 22.5 \\
No information & 18 & 15 & 33 & 18.5 \\
Total & 137 & 41 & 178 & 100 \\
\hline
\end{tabular}

nymph in 2019. In 2020, we had one first-stage nymph, one second-stage nymph, two fourth-stage nymphs, and one fifth-stage nymph.

From 2019 to 2020, 178 T. williami were collected. Sixty percent of them were found inside the domiciles, $22 \%$ in the peridomicile, and we did not have any information for $18 \%$ of them. For intradomicile environments, bedrooms and living rooms were the most infested (Table 2).

We observed a seasonality pattern from a monthly density analysis of the sampled triatomines from 2019 to 2020. Such a pattern was associated with the increase in the sampled triatomine in the third quarter of the

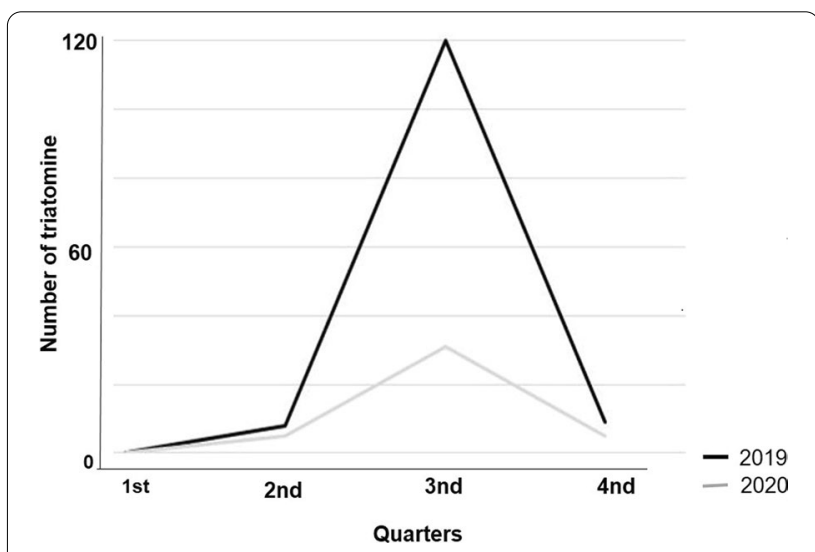

Fig. 2 The number of Triatoma williami collected between 2019 and 2020 in Barra do Garças, Mato Grosso, Brazil 
respective years analyzed. This period was recorded as the driest climatic season in the region (Fig. 2).

\section{Natural infection by $T$. cruzi}

A total of 211 triatomine specimens were collected between 2019 and 2020. It was possible to assess the natural infection in 132 specimens from these samples. Of the 132 triatomine specimens analyzed, 52 (39.4\%) were naturally infected with $T$. cruzi, revealing a high natural infection rate. T. williami had a higher infection prevalence (Table 3). Four triatomine species were found naturally infected. The natural infection rate in descending order according to species was $43.6 \%$ (48/110), 33.3\% $(1 / 3)$ for P. diasi and P. geniculatus, and $12.5 \%(2 / 16)$ for
R. neglectus. T. williami had the highest infection prevalence, which reached 92\% (48/52), representing the most significant risk for the human population in Barra do Garças.

\section{T. williami in the process of domiciliary colonization}

In September 2019, in one searched bed, the field agents found four adult specimens (Fig. 3A, one male and three female), 34 eggs, and 41 nymphs in the first developmental stage (N1) on the wooden bed frame (Fig. 3B, C). Signs of feces were also observed.

After these triatomine specimens were found, the endemic control agents of the city health secretary from Barra do Garças conducted a residual chemical

Table 3 The natural infection for Trypanosoma cruzi according to triatomine species collected in Barra do Garças, Mato Grosso, Brazil, for 2019 to 2020

\begin{tabular}{lcccr}
\hline Species & No. of specimens analyzed & No. of positive & Infection rate (\%) & $\begin{array}{c}\text { Infection } \\
\text { prevalence } \\
\text { (\%) }\end{array}$ \\
\hline Triatoma williami & 110 & 48 & 43.6 & 92.3 \\
Rhodnius neglectus & 16 & 2 & 12.5 & 3.8 \\
Panstrongylus diasi & 3 & 1 & 33.3 & 1.9 \\
P.geniculatus & 3 & 52 & 33.3 & 1.9 \\
Total & 132 & 39.4 & 100.0 \\
\hline
\end{tabular}

Data recorded in the monthly sheet of the ChD Control Program, SESMT.Brazil. Unpublished data

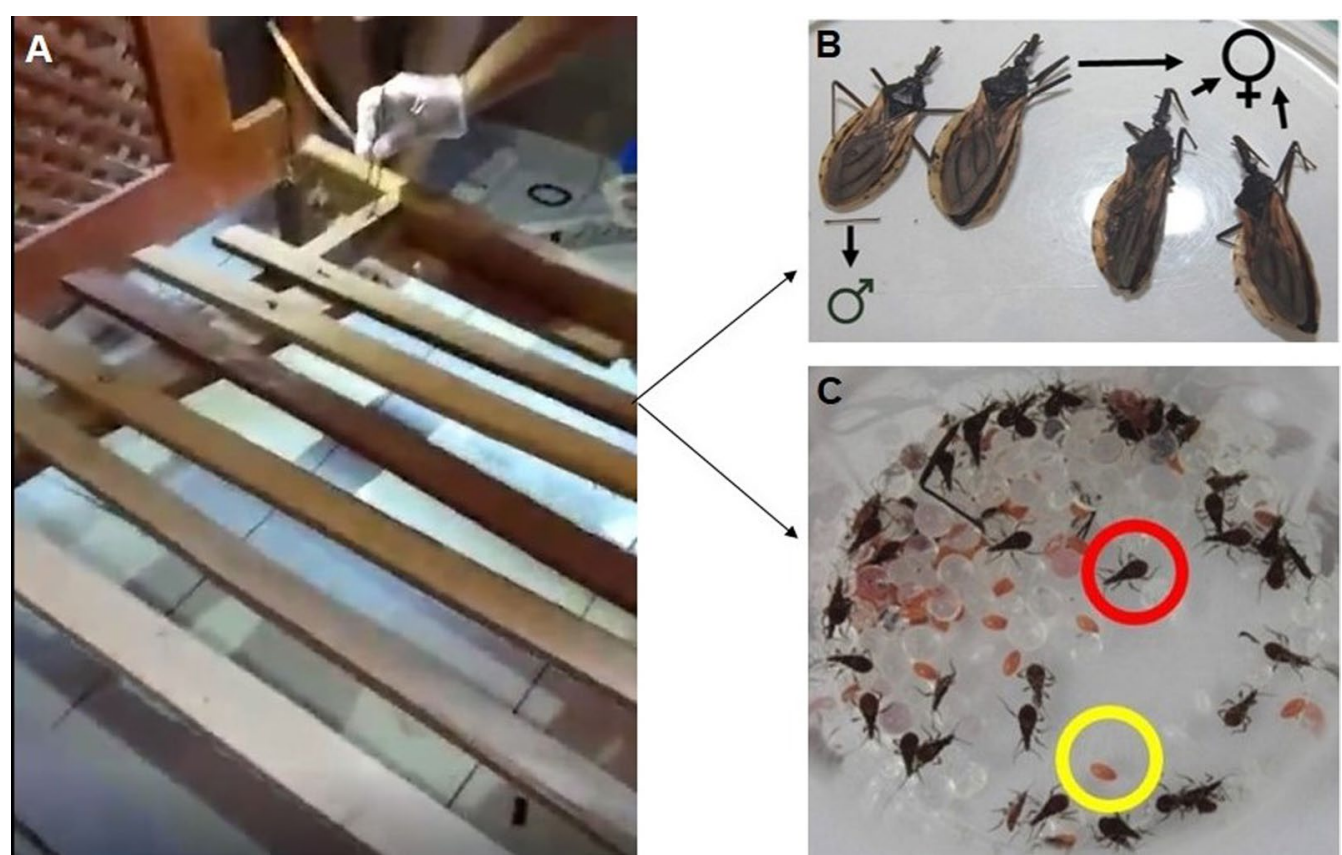

Fig. 3 A The field agents performed an entomological survey in the cracks of resident bed; $\mathbf{B}$ One male and three female specimens of Triatoma williami; C Eggs (yellow circle) and nymphs (red circle) collected in Barra do Garças, Mato Grosso, Brazil, in 2019 
control in that domicile. In 2020, no entomological research or chemical control were performed in this domicile. In January 2021, more specimens were caught by residents inside their domiciles. These specimens were handed over to the ERSBG from the SESMT. This was the second compound domiciliation record with eight sampled specimens: two males, one female, and five nymphs (one nymph in the N1, one in the N2, two in the N4, and one in the N5 stages).

In February 2021, the field agents carried out residual chemical control in the infested domicile. In June 2021, the resident on that infested domicile collected and delivered two additional T. williami nymphs to the ERSBG from the SESMT: one nymph in the N1 stage, one dead male, and one exuviae (Fig. 4).

T. williami colonies were found in beds indoors in an urban area in the Jardim Pitaluga neighborhood (Fig. 1) in Barra do Garças, Mato Grosso, Brazil. Voucher specimens from the first colony were deposited in the Herman Lent Collection of the Instituto Oswaldo Cruz in Rio de Janeiro, Brazil, being two adults: CTIOC13005, CTIOC13006; three nymphs (CTIOC13007 to CTIOC13009) and five eggs.

Two adult specimens, one female and one male, and two nymphs from the second T. williami colony were deposited in the "Entomological Collection Prof. Dr. José Maria Soares Barata" in the Faculty of Pharmaceutical Sciences UNESP-Araraquara-São Paulo Brazil. Therefore, domiciliary colonization by two T. williami

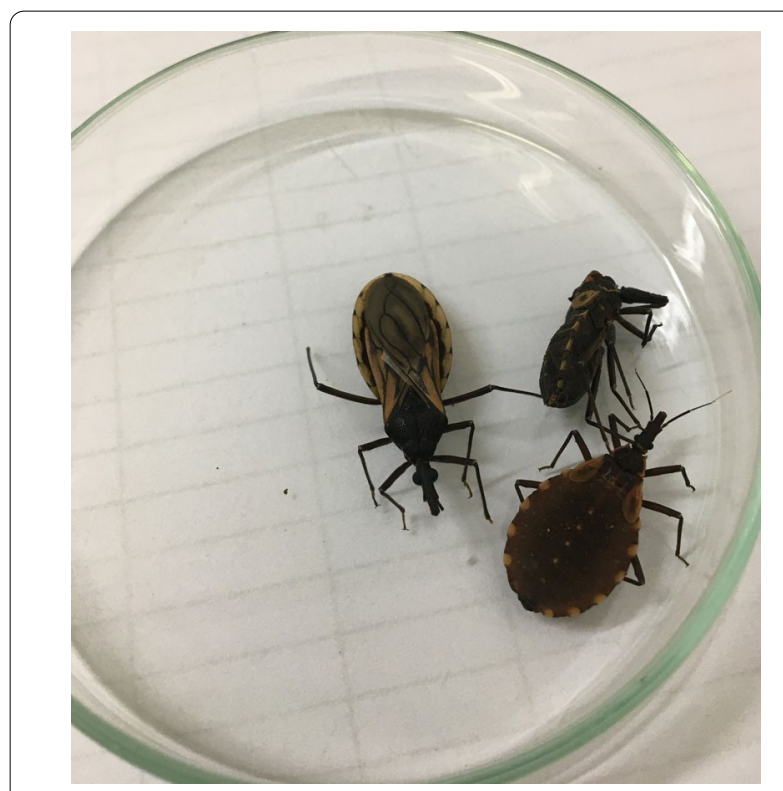

Fig. 4 The specimens of Triatoma williami sampled after the residual chemical control in Barra do Garças, Mato Grosso, Brazil, in 2021 colonies found in an urban area in Barra do Garças, Mato Grosso, Brazil, was reported in this study.

\section{Identification of the $T$. cruzi strain}

For the first colony, two adult female specimens were positive for $T$. cruzi in the parasitological diagnosis being submitted to the molecular diagnosis and later to the genetic sequencing. The DTU type IV of the T. cruzi strain was revealed by the identification results.

\section{Discussion}

In a seven-year historical series, the invasion of wild triatomine species has been reported in urban domiciles from Barra do Garças, Mato Grosso, Brazil. T. williami was the primary specimen detected. The identification of T. williami was conducted based on external morphological characteristics. In such analyses, the importance of these structures in the identification of specimens was confirmed, as previously discussed by Teves et al. [37].

We reported the findings of all development stages of T. williami: adults, nymphs, and eggs inside human domicile from Barra do Garças, Mato Grosso, Brazil, during two different years. In the second year, we found nymphs in the last developmental stage, suggesting early stages in the domestication of this sylvatic species. The domiciliary colonization of wild triatomine species is a risk factor for reestablishing the vectorial transmission of $\mathrm{ChD}[15$, 38]. The record of T. williami in the domiciliation process should be problematic because of the record of this species naturally infected by $T$. cruzi with a high infection rate.

So far, T. williami has been considered a secondary $T$. cruzi vector because it maintains its wild condition and shows synanthropic potential, colonizing the peridomicile and frequently invading the domiciles. Synanthropy represents a secondary adaptation by sylvatic species in response to environmental changes. Such adaptability to domiciles depends on triatomine plasticity [17]. One study [39] mentioned that morphological plasticity in the shape of T. williami is associated with blood source, but they did not test whether plasticity confers a fitness advantage to culminate in domiciliation by this species. However, a high potential vector for nymphs of this species was recorded in a previous study [40].

The first T. williami specimen in Nova Xavantina, Mato Grosso, Brazil, was recorded by Travassos-Filho (1972) [41]. This specimen was collected inside the domicile of a worker and infected with T. cruzi. Then Arrais-Silva et al. (2011) and Andrade-Neto et al. (2012) $[26,27]$, using molecular biology, found that the natural infection rate of this species by T. cruzi was $30 \%$ in Barra do Garças, Mato Grosso, Brazil. We observed an elevated infection rate of T. williami by T. cruzi in 2019 
and 2020 in our parasitological feces diagnosis, indicating the transmission risk of the parasite by this vector.

The finding of the TcIV DTU of T. cruzi in T. williami collected at home is an unprecedented record for Mato Grosso, Brazil, and is worrisome. Although this DTU originates from the wild cycle, studies have already demonstrated its participation in domestic cycles [42, 43] that are frequently correlated with acute illnesses caused by $\mathrm{ChD}$ in humans. These cases are mainly associated with outbreaks of oral transmission of the parasite, with TcIV being one of the leading causes of human ChD in the western Brazilian Amazon [44-46]. Thus, the transmission risk of the parasite to humans in the region might be increased by the occurrence of triatomine colonies infected by this strain in domicile environments.

The distribution of DTU TcIV is the most important in Central and South America, with greater density in the Amazon region $[42,43]$. In studies analyzing triatomines from different biomes, this DTU has not been recorded in the Cerrado [47], the predominant biome in our study area. With the finding of this strain in T. williami, we corroborate previous records related to the historical predominance of this DTU for the genus Triatoma [47].

Surveillance for species, considering the domiciliation principle, and the development of actions to interrupt the vector domiciliation process, is paramount in preventing $\mathrm{ChD}$. The occurrence of wild triatomine species sporadically invading human domiciles is a significant difficulty in vector surveillance programs [48]. It is necessary to carry out immediate intervention to interrupt this domiciliation process of T. williami in the urban area of Barra do Garças, Mato Grosso, Brazil. The approximation of vectors with human living spaces increases the risk of transmission of ChD [49].

Analysis of the triatomines collected in Barra do Garças in a historical seven-year series showed earlier demonstrates the increase in vector density in 2019. Periods with a peak incidence of triatomines in the third quarter of the year are indicated by the results. Seasonality is also observed in Chagas vector populations and transmission. In combination with density-dependent regulation, these characteristics have led to the belief that insecticide control of these vectors can be improved if seasonally timed $[50,51]$.

When we analyzed the records of the locations with triatomines in Barra do Garças over seven years, we identified a higher occurrence in domicile in the four neighborhoods bordering PESA. Thus, the presence of a green belt associated with the artificial light of these domicile holds might support and promote the dispersion of triatomines. Martins et al. [29] reported that the proximity of Barra do Garças to PESA may facilitate human contact with triatomines, which are potential vectors of ChD, especially in PESA neighborhoods.

In a study in a similar area, Jácome-Pinilla et al. [52] proved an actively dispersing area, and triatomines highly attracted to artificial lights. Furthermore, the environmental parameters encountered during this study, particularly during the first hours after sunset, are favorable for the active dispersal of sylvatic triatomines. One immediate recommendation is that external artificial lights on walls must remain turned off during the first hours after sunset, the period when most sylvatic. Triatomines find favorable atmospheric and environmental conditions for dispersal.

Entomological surveillance for triatomines in Barra do Garças has been done mainly by the population, showing the importance of passive surveillance by residents to detect foci of the triatomines. Passive surveillance improved risk management by the city health system, favoring timely intervention in the $\mathrm{ChD}$ transmission chain. This process is in agreement with entomological surveillance, which has been supported by community referees responsible for the Triatomine Information Post Network [38]. The population's knowledge about triatomines and $\mathrm{ChD}$ is paramount to promoting collaboration in vector control and reducing vector transmission [53-55].

The primary limitation of this study was the COVID19 pandemic. Because the domicile visits were reduced along with the communication of new triatomine specimens being caught, the number of specimens analyzed in 2020 was lower than in the other years. Another limiting factor was the number of dead triatomines delivered by residents, impairing the parasitological diagnosis of the presence of T. cruzi in these specimens.

\section{Conclusion}

As far as we know, this study is the first to confirm the domiciliation of $T$. williami in urban areas of Barra do Garças, Mato Grosso, Brazil. This record occurred after sporadic invasions by this species in domiciles near an environmental conservation unit. This park is composed of native vegetation and wild animals, reservoirs for $T$. cruzi. These conditions reinforce the importance of entomological surveillance for the sanitary control of triatomines. Further studies are needed to better understand the ecology of these species for their prevention and control mechanisms, since they have a high natural infection rate by $T$. cruzi.

\section{Abbreviations}

CTIOC: Collection of the Instituto Oswaldo Cruz; ChD: Chagas disease; CNPq: Conselho Nacional de Desenvolvimento Científico e Tecnológico; DTUs:

Discrete typing units; ERSBG: Escritório Regional de Saúde de Barra do Garças; 
IBGE: Instituto Brasileiro de Geografia e Estatística; PCR: Polymerase chain reaction; PESA: Parque Estadual da Serra Azul; PCDCh: Chagas disease contro program; SMS: Secretaria Municipal de Saúde; SESMT: Secretaria de Estado de Saúde de Mato Grosso; WHO: World Health Organization.

\section{Supplementary Information}

The online version contains supplementary material available at https://doi. org/10.1186/s40249-022-00938-4.

Additional file: Table S1. Species of triatomines with a tendency toward the domiciliation process (presence of eggs/nymphs and adults) in human domiciles.

Additional file 2: Figure S1. Panoramic view of the Barra do Garças municipality and the PESA, Mato Grosso, Brazil.

Additional file 3: Figure S2. A. Adult female of T. williami; B. Head detail in the dorsal view of the specimens; $C$. wing venation pattern detail of the specimens; D. External female genitalia by dorsal view; E. General appearance of the connexivum chromatic pattern.

Additional file 4: Figure S3. The absolute and relative frequencies of triatomines collected in Barra do Garças, Mato Grosso, Brazil, from 2013 to 2020.

\section{Acknowledgements}

To Secretaria de Estado de Saúde de Barra do Garças, Mato Grosso, Brazil, for supporting surveillance actions in health. To ACEs da Secretaria Municipal de Saúde de Barra do Garças, Mato Grosso, Brazil, responsible for Chagas disease surveillance, and Ana Gomes da Silva for carrying out the parasitological diagnosis of feces. To residents for passive surveillance of triatomines. JO would like to thank the São Paulo State Research Support Foundation (FAPESP, Brazil). JCS would like to thank the Coordination for the Improvement of Higher Education Personnel (CAPES, Brazil) for the M.Sc. fellowship.

\section{Authors' contributions}

MFM, JCS, and JO contributed to the preparation of the manuscript; CG was responsible for identifying the studied specimens and text review; SCM organized, prepared, and analyzed the data; and LKSS realized textual revision. All authors read and approved the final manuscript.

\section{Funding}

Foundation Project: Supported by Fundação de Amparo à Pesquisa do Estado de Mato Grosso (No. 276237/18-PPPSUS) and Conselho Nacional de Desenvolvimento Científico e Tecnológico (CNPq).

\section{Availability of data and materials}

Specimens from this study were deposited in the Herman Lent Collection of the Instituto Oswaldo Cruz in Rio de Janeiro, Brazil, and in the Entomological Collection Prof ${ }^{\circ}$ Dr. José Maria Soares Barata, in the Faculty of Pharmaceutical Sciences UNESP_Araraquara—São Paulo, Brazil.

\section{Declarations}

Ethics approval and consent to participate Not applicable.

\section{Consent for publication}

Not applicable.

\section{Competing interests}

The authors declare that they have no competing interests.

\section{Author details}

${ }^{1}$ Department of Environmental Health Surveillance, State Health Secretary of Mato Grosso-SESMT, Amaro Leite 474, Barra do Garças, MT 78600-027, Brazil. ${ }^{2}$ Public Health Faculty, Public Health Entomology Lab, University of São Paulo, São Paulo, SP, Brazil. ${ }^{3}$ Institute of Biological and Health Science, Federal
University of Mato Grosso, Barra do Garças, MT 78600-000, Brazil. ${ }^{4}$ National and International Triatomini Taxonomy Reference Lab, Instituto Oswaldo CruzIOC, FIOCRUZ, Av. Brasil 4365, Pavilhão Rocha Lima, Sala 505, Rio de Janeiro, RJ 21040-360, Brazil.

Received: 25 August 2021 Accepted: 18 January 2022

Published online: 14 February 2022

\section{References}

1. Galvão C. Taxonomia dos vetores da doença de Chagas da forma à molécula, quase três séculos de história. In: Oliveira J, Alevi KC, Camargo LMA, Meneguetti DUO, editors. Atualidades em medicina tropical no Brasil: vetores. Rio Branco: Stricto Sensu; 2020. p. 9-37.

2. Galvão C. Vetores da doença de chagas no Brasil (Zoologia: guias e manuais de identificação series). Curitiba: Sociedade Brasileira de Zoologia; 2014

3. Souza ES, Von Atzingen NCB, Furtado MB, Oliveira J, Nascimento JD, et al. Description of Rhodnius marabaensis sp. N. (Hemiptera, Reduviidae, Triatominae) from Pará State, Brazil. Zookeys. 2016;621:45-62. https://doi. org/10.3897/zookeys.621.9662.

4. Alevi KCC, Oliveira J, Garcia ACC, Cristal DC, Delgado LMG, de Freitas BI, et al. Triatoma rosai sp. Nov. (Hemiptera, Triatominae): a new species of Argentinian Chagas disease vector described based on integrative taxonomy. Insects. 2020;11(12):830. https://doi.org/10.3390/insects111 20830.

5. Zhao Y, Galvão C, Cai W. Rhodnius micki, a new species of Triatominae (Hemiptera, Reduviidae) from Bolivia. ZooK. 2021;1012:71-93. https://doi. org/10.3897/zookeys.1012.54779.

6. Dale C, Justi AS, Galvão C. Belminus santosmalletae (Hemiptera: Heteroptera: Reduviidae): new species from Panama, with an updated key for Belminus Stål, 1859 species. Insects. 2021;12:686. https://doi.org/10.3390/ insects12080686

7. Silva MBA, Menezes KR, Siqueira AM, Balbino VQ, Lorosa ES, Farias MCG, et al. Importância da distribuição geográfica dos vetores da doença de chagas em Pernambuco, Brasil, em 2012. Rev Patol Trop. 2015;44(2):195206. https://doi.org/10.5216/rpt.v44i2.36650.

8. da Saúde M. Secretaria de Vigilância em Saúde. Bol Epidemiol. 2015;46:21.

9. Oliveira J, Alevi KCC. Taxonomic status of Panstrongylus herreri Wygodzinsky, 1948 and the number of Chagas disease vectors. Rev Soc Bras Med Trop. 2017:50(3):434-5. https://doi.org/10.1590/0037-8682-0125-2017.

10. Monteiro FA, Weirauch C, Felix M, Lazoski C, Abad-Franch F. Evolution, systematics, and biogeography of the triatominae, vectors of Chagas disease. Adv Parasitol. 2018;99:265-344. https://doi.org/10.1016/bs.apar. 2017.12.002.

11. Abad-Franch F, Diotaiuti L, Gurgel-Gonçalves R, Gürtler RE. Certifying the interruption of Chagas disease transmission by native vectors: cui bono? Mem Inst Oswaldo Cruz. 2013;108(2):251-4. https://doi.org/10.1590/ 0074-0276108022013022.

12. Brandão HR, Fonseca EOL, Santos RF, Ribeiro-Júnior G, Santos CGS, Cova BO, et al. Descrição de focos residuais de Triatoma infestans (Klug, 1834) no município de Novo Horizonte, Bahia. Rev Baiana Saúde Públ. 2015;39(1):91-104. https://doi.org/10.5327/Z0100-0233-201539S100009.

13. Vinhaes MC, Oliveira SV, Reis PO, Sousa ACL, Silva RA, Obara MT, et al. Assessing the vulnerability of Brazilian municipalities to the vectorial transmission of Trypanosoma cruzi using multi-criteria decision analysis. Acta Trop. 2014;137:105-10. https://doi.org/10.1016/j.actatropica.2014.05. 007.

14. Schofield CJ, Diotauiti L, Dujardin JP. The process of domestication in Triatominae. Mem Inst Oswaldo Cruz. 1999;l:375-8. https://doi.org/10. 1590/S0074-02761999000700073.

15. Waleckx E, Gourbière S, Dumonteil E. Intrusive versus domiciliated triatomines and the challenge of adapting vector control practices against Chagas disease. Mem Inst Oswaldo Cruz. 2015;110(3):324-38. https://doi. org/10.1590/0074-02760140409.

16. Lent H, Wygodzinsky P. Revision of the Triatominae (Hemiptera, Reduviidae), and their significance as vectors of Chagas Disease. Bu Amer Mu Na Hist. 1979. http://hdl.handle.net/2246/1282. 
17. Forattini OP. Biogeografia, origem e distribuição da domiciliação de triatomíneos no Brasil. Rev Saúde Públ. 1980;14:265-99. https://doi.org/ 10.1590/S0034-89102006000700004.

18. Silveira AC. Current situation with chagas disease vector control in the Americas. Cad Saude Publica. 2000;16(Suppl 2):35-42. https://doi.org/10. 1590/S0102-311X2000000800004 (in Portuguese).

19. World Health Organization. Control of Chagas disease, Techn. Geneva: Re Ser; 2002. p. 905.

20. Carbajal de la Fuente AL, Dias-Lima A, Lopes CM, Emperaire L, Walter A, Ferreira A, et al. Behavioral plasticity of triatominae related to habitat selection in northeast Brazil. J Med Entomol. 2008;45:14-9. https://doi. org/10.1093/jmedent/45.1.14

21. Noireau F, Dujardin JP. Biology of Triatominae. In: Telleria J, Tibayrenc M, editors. American trypanosomiasis: Chagas disease one hundred years of research. Burlington: Elsevier; 2010. p. 870.

22. Valente VC. Potential for domestication of Panstrongylus geniculatus (Latreille, 1811) (Liemiptera, Reduviidae, Triatominae) in the municipality of Muaná, Marajó Island, State of Pará, Brazil (sic). Mem Inst Oswaldo Cruz. 1999;94:399-400. https://doi.org/10.1590/S0074-02761999000700078.

23. Galvão C, Rocha DS, Juberg J, Carcavallo RU. Ampliação da distribuição geográfica de Triatoma deaneorum Galvão, Souza \& Lima, 1967, nova denominação para Triatoma deanei (Hemiptera, Reduviidae). Rev Soc Bras Med Trop. 2001;34:587-9. https://doi.org/10.1590/S0037-8682200100 0600015.

24. Soto-Vivas A, Bazarte H, Fernandéz DM. Primer registro de Eratyrus mucronatus Stål, 1959 (Hemiptera: Reduviidae) en el ambiente domiciliário em Venezuela (sic). Entomotropica. 2001;16:215-217. http://hdl.handle.net/ $1807 / 5758$.

25. Almeida PS, Ceretti Júnior W, Obara MT, Santos HR, Barata JMS, Faccenda O. Levantamento da fauna de Triatominae (Hemiptera: Reduviidae) em ambiente domiciliar e infecção natural por Trypanosomatidae no Estado de Mato Grosso do Sul. Rev Soc Bras Med Trop. 2008;41(4):374-80. https://doi.org/10.1590/S0037-86822008000400010.

26. Arrais-Silva WW, Rodrigues RSV, de Moraes LN, Venere PC, Lunardi RR, Souza IL, et al. First report of occurrence of Triatoma williami Galvão, Souza e Lima, 1965 naturally infected with Trypanosoma cruzi Chagas, 1909 in the State of Mato Grosso, Brazil. Asian Pac J Trop Dis. 2011;1(3):245-6. https://doi.org/10.1016/S2222-1808(11)60040-6.

27. Andrade-Neto OA, de Arruda MCC, Kerkho J, Lunardi RR, Arrais-Silva WW. Risk of domiciliation of Triatoma williami Galvão, Souza e Lima, 1965 in a municipality of Brazilian Legal Amazon region. Asian Pac J Trop Dis. 2012;2(1):265-7. https://doi.org/10.1016/S2222-1808(12)6.

28. Instituto Brasileiro de Geografia e Estatística (IBGE). 2021. Accessed 09 de Mar 2021. Disponível em http://www.ibge.gov.br/cidadesat/topwindow. htm?1.

29. Martins MF, Moraes SC, Obara MT, Galvão C. Panstrongylus diasi Pinto \& Lent, 1946 (Hemiptera, Reduviidae, Triatominae): first record in Mato Grosso, Brazil. Check List. 2019;15(2):259-64. https://doi.org/10.15560/ 15.2.259.

30. FEMA—Fundação Estadual do Meio Ambiente-MT. Diagnóstico Ambiental do Parque Estadual da Serra Azul. Barra do Garças: SEMA. 2000.

31. Ministério do Meio Ambiente (MMA) Secretaria de biodiversidade e florestas. Avaliação e identificação de áreas e ações prioritárias para conservação, utilização sustentável e repartição dos benefícios da biodiversidade nos biomas brasileiros. Brasília. 2002.

32. Silva JMC, Bates JM. Biogeographic patterns and conservation in the South American Cerrado: a tropical savanna hotspot. Bioscience. 2002;52:225-34. https://doi.org/10.1641/0006-3568(2002)052[0225: BPACIT]2.0.CO;2.

33. Köppen W. Climatologia: comun estudio de los climas de la tierra. Fondo de Cultura Economica, México, 1948.

34. Brígido RTS, Tavares PCB, Santos MA, Santos JG, Souza MA, Goulart IMB, Silva CV. Trypanosoma cruzi modulates gene expression of plasma membrane repair-related proteins. Acta Trop. 2017;174:153-7. https://doi.org/ 10.1016/j.actatropica.2016.06.008.

35. Cosentino RO, Aguëro F. A simple strain typing assay for Trypanosoma cruzi: Discrimination of major evolutionary lineages from a single amplification product. PLoS Negl Trop Dis. 2012;6(7): e1777. https://doi.org/10. 1371/journal.pntd.0001777.

36. Sievers F, Higgins DG. Clustal omega. Curr Protoc Bioinf. 2014;48(1):3-13. https://doi.org/10.1002/0471250953.bi0313s48.
37. Teves SC, Gonçalves TCM, de Freitas SPC, Lopes CM, Carbajal-de-la-Fuente AL, Santos-Mallet JR. External female genitalia of Triatoma jatai, Triatoma costalimai and Triatoma williami (Hemiptera: Reduviidae: Triatominae). Parasit Vectors. 2020. https://doi.org/10.1186/s13071-020-04418-2.

38. Silveira AC, Dias JCP. The control of vectorial transmission. Rev Soc Bras Med Trop. 2011;44(2):52-63. https://doi.org/10.1590/S0037-8682201100 0800009.

39. Lunardi RR, Benítez HA, Câmara TP, Gomes PL, Arrais-Silva WW. Head variation in response to diet of Triatoma williami (Galvão, Souza e Lima, 1965). Zool Anz. 2017;266: 187193. https://doi.org/10.1016/j.jcz.2017.04.001.

40. Lunardi RR, Gomes LP, Câmara TP, Arrais-Silva WW. Life cycle and vectorial competence of Triatoma williami (Galvão, Souza e Lima, 1965) under the influence of different blood meal sources. Acta Trop. 2015;149:220-6. https://doi.org/10.1016/j.actatropica.2015.05.023.

41. Travassos Filho LP. Triatoma williami Galvão, Souza e Lima, 1965, captured in Mato Grosso. Brazil, new vector of Chagas disease. Mem Inst Butantan. 1972;36:263-6 (In Portuguese).

42. Zingales B, Miles MA, Campbell DA, Tibayrenc M, Macedo AM, Teixeira MM et al. The revised Trypanosoma cruzi subspecific nomenclature: rationale, epidemiological relevance and research applications. Infect Genet Evol. 2012;12:240-53. https://doi.org/10.1016/j.meegid.2011.12.009.

43. Breniére SF, Waleckx E, Barnabé C. Over six thousand Trypanosoma cruzi strains classified into discrete typing units (DTUs): attempt at an inventory. PLoS Negl Trop Dis. 2016;10(8): e0004792. https://doi.org/10.1371/ journal.pntd.0004792.

44. Monteiro WM, Magalhães LK, de Sá AR, Gomes ML, Toledo MJ, Borges L, et al. Trypanosoma cruzi IV causing outbreaks of acute Chagas disease and infections by different haplotypes in the Western Brazilian Amazonia. PLoS ONE. 2012;7(7): e41284. https://doi.org/10.1371/journal.pone.0041284.

45. Teston APM, Abreu AP, Abegg CB, Gomes LM, Toledo MJO. Outcome of oral transmission in mice inoculated with Trypanosoma cruzi IV of the Western Brazilian Amazon. Acta Trop. 2017;166:212-7. https://doi.org/10. 1016/j.actatropica.2016.11.019.

46. Santana RAG, Guerra MGVB, Sousa DR, Couceiro K, Ortiz JV, Oliveira M, et al. Oral transmission of Trypanosoma cruzi, Brazilian Amazon. Emerg Infect Dis. 2019;25(1):132-5. https://doi.org/10.3201/eid2501.180646.

47. Barros JHS, Xavier SCC, Bilac D, Lima VS, Dario MA, Jansen AM. Identification of novel mammalian hosts and Brazilian biome geographic distribution of Trypanosoma cruzi Tclll and TcIV. Acta Trop. 2017;172:173-9. https://doi.org/10.1016/j.actatropica.2017.05.003.

48. Caranha L, Gurgel-Gonçalves R, Ramalho RD, Galvão C. New records and geographic distribution map of Triatoma petrocchiae Pinto and Barreto, 1925 Hemiptera: Reduviidae: Triatominae. Check List. 2011;7(4):508-9. https://doi.org/10.15560/7.4.508.

49. Carvalho DM, Gomes WS. Distribuição de triatomíneos hemíptera, Reduviidae, Triatominae nos municípios da mesorregião sul do estado do Ceará, no período de 2010 a 2012. Cadernos ESP. 2014;8(2):30-37. http:// cadernos.esp.ce.gov.br/index.php/cadernos/article/view/128.

50. Gorla DE. Seasonal effects on control strategies of Chagas' disease vectors. Rev Argent Microbiol. 1988;20(1):71-80.

51. Schofield CJ. Vector population responses to control interventions. Ann Soc Belg Med Trop. 1991;71(1):201-17.

52. Jácome-Pinilla D, Hincapie-Peñaloza E, Ortiz MI, Ramírez JD, Guhl F Molina J. Risks associated with dispersive nocturnal flights of sylvatic Triatominae to artificial lights in a model domicile in the northeastern plains of Colombia. Parasit Vectors. 2015;8:600. https://doi.org/10.1186/ s13071-015-1209-3.

53. Villela MM, Souza JM, Melo Vde P, Dias JC. Evaluation of the Chagas Disease Control Program and presence of Panstrongylus megistus in centralwestern Minas Gerais State, Brazil. Cad Saude Publica. 2009;25(4):907-17. https://doi.org/10.1590/s0102-311×2009000400022 (In Portuguese).

54. Villela MM, Pimenta DN, Lamounier PA, Dias JC. Evaluation of knowledge and practices related to Chagas disease and its vectors among adults and children in an endemic region in Minas Gerais State. Brazil Cad Saude Publica. 2009;25(8):1701-10. https://doi.org/10.1590/s0102-311×200900 0800006.(InPortuguese).

55. Coura JR, Junqueira ACV. Risks of endemicity, morbidity and perspectives regarding the control of Chagas disease in the Amazon Region. Mem Inst Oswaldo Cruz. 2012;107(2):145-54. https://doi.org/10.1590/S0074-02762 012000200001. 